\title{
Effects of Shelling Ratio and Particle Characteristic on Physical Properties of Three-Layered Particleboard Made from Different Wood Species
}

\author{
Muhammad Navis Rofii, Satomi Yumigeta, Shigehiko Suzuki, and T. Agus Prayitno
}

\begin{abstract}
Wood waste materials such as flakes, particles, sawdust, planer shaving, which are residues from furniture industry can be utilized to manufacture many composites such as particleboard. The most commonly used particleboard has three layers: two face layers and one core layer. The face layers consist of fine particles and the core layer is made of coarse particles.This study aimed to show the effect of shelling ratio and particle characteristic on physical properties of three-layer particleboard with high density core and different particles on surface layers. The materials used in this study were hinoki (Chamaecyparis obtusa) strand and knife-milled Douglas-fir (Pseudotsuga manziesii) as surface layers and hammer-milled matoa (Pometia sp.) as core layer. The wood particles were collected from a wood company. Adhesive used was MDI resin (methylene diphenyl diisocyanate) with $6 \%$ content in mat preparation. The pressing conditions were: temperature $180^{\circ} \mathrm{C}$, pressure $3 \mathrm{MPa}$ and pressing time $5 \mathrm{~min}$. The target density was $0.72 \mathrm{~g} / \mathrm{cm}^{3}$ with board size of $340 \mathrm{~mm} \times 320 \mathrm{~mm} \times 10 \mathrm{~mm}$. Factors used in this study were layer structure according to board shelling ratio and particle characteristic. The parameters of this study were density, moisture content, thickness swelling, water absorption, linear expansion and vertical density profile.

The results of this study indicate that all boards meet the requirements of JIS A 5908-2003. Higher shelling ratio of surface layers resulted in higher physical performance of three-layer particleboard. In terms of particle type, hinoki strands showed the best performance in board density and linear expansion, while Douglas-fir particle showed the best performance in moisture content, thickness swelling and water absorption. Improvement of physical properties of particleboard with high density wood particles in core layer can be conducted by adding surface layer with higher quality wood particles such as hinoki strands or Douglas-fir particles. Compared to Douglas-fir particles, hinoki strands as surface layers contribute to higher enhancement of three-layer particleboard with matoa as the core layer.
\end{abstract}

Keywords: shelling ratio, particle characteristic, three-layer particleboard, physical properties.

\section{Introduction}

Wood supply is decreasing fast around the world while wood product demand is increasing parallel to the total world population. Thus, the wood products become in scarcity and their prices climb up fast. Biocomposites technology is developed in order to supply alternative wood products. This technology converts some waste of the conventional wood processing to useful products by using wood adhesion technology. Wood composites can utilise low grade logs such as thinnings and bowed and twisted logs. They can also use wood waste material. There are many kinds of wood waste from furniture industry such as flakes, particles, sawdust and planer shaving. These residues can be utilized as raw materials for manufacturing many composites such as particleboard. Knife-milled Douglas-fir or hammer-milled hinoki -both are softwood- can be used for this purpose. Hinoki is the second most common wood in Japan and its wood waste can be found easily in furniture industry companies in Japan. Matoa, a hardwood species, has potential to be used for particleboard production although its particles are originally low quality.

Particleboard is mainly composed of wood particles and an adhesive. Wood particles are mixed or coated with an adhesive and then formed into a mat that is further hotpressed to form a panel product (Youngquist 1999). The most commonly used particleboard has three layers: two face layers and one core layer. Structures of these layers differ markedly. The face layers consist of fine particles and the core layer is made of coarse particles. The face layers, made of smaller chips with a higher resin content, have a greater compaction ratio and density and in consequence better mechanical properties than the core layers (Wilczynski and Kociszewski 2010).

It is well known that wood species and particle size used influence the bending strength of three-layer particleboard. Important indicators of particleboard quality are their mechanical and physical properties. Moslemi (1974) and Maloney (1993) determined that with decreasing density of raw materials and increasing compaction ratio, the bending strength increases as well. According to Moslemi (1974), there are several options in order to obtain high quality particleboards according to layering such as: (a) a higher adhesive content in the face layer, (b) different particles in the face layer (smaller, thinner), (c) lower density wood species in the face layer, (d) processing techniques which reduce compression strength of the face particles, and (e) surface particle orientation is kept constant. In this study, second and third options were applied.

There are two different elastic components (surface and core layer) in three-layer particleboard using matoa as core layer and hinoki/Douglas-fir as surface layer. The question is how the layer structure and particles type affect 
the quality of particleboard made from different wood species. This study aimed to show how layer structure enhance the physical properties of 3-layers board with high density core layer (matoa hammermilled particles). Therefore, the objectives of this study was to determine the effect of layer structure related to its shelling ratio and particle characteristic on the physical properties of particleboard produced from different sources of wood particles.

\section{Materials and Methods}

\section{Boards Manufacturing}

The particles used in this study were hinoki (Chamaecyparis obtusa) strands and knife-milled Douglasfir (Pseudotsuga manziesii) as surface layer and hammermilled matoa (Pometia sp.) as core layer. Those wood particles were collected from a wood company. Adhesive used was MDI resin (methylene diphenyl diisocyanate) with $6 \%$ content in mat preparation. A blending box was used to mix the particles and resin adhesive. The mixed adhesivewood particles were placed in a forming box by hand to form a one and three layer of wood particle mat. The resulting three-layer wood particle mat was hand-pressed with a flat plywood panel and then hot-pressed. Pressing conditions were: temperature $180^{\circ} \mathrm{C}$, pressure $3 \mathrm{MPa}$ and pressing time $5 \mathrm{~min}$. The target density was $0.72 \mathrm{~g} / \mathrm{cm}^{3}$ with board size of $340 \mathrm{~mm} \times 320 \mathrm{~mm} \times 10 \mathrm{~mm}$. Three particleboard panels were prepared for each experimental variable, therefore 27 pieces particleboards were produced. After manufactured, the boards were kept in the conditioning room for approximately two weeks.

\section{Boards Evaluation}

The parameters of this study were Density $(\rho)$, Moisture Content (MC), Thickness Swelling (TS), Water Absorption (WA), Linear Expansion (LE) and Vertical Density Profile (VDP). Prior the evaluation, the boards were cut into size of $280 \times 280 \mathrm{~mm}$, and then the density was measured $(\rho)$ by measuring its weight $(w)$ and volume $(v)$. Boards density was calculated as follow:

$\rho=\frac{w}{w}\left(\mathrm{~g} / \mathrm{cm}^{2}\right)$

MC of particleboards manufactured was measured by specimens of $50 \times 50 \mathrm{~mm}$ in size. Six specimens were used for each treatment. The specimens were measured in weight $\left(\boldsymbol{W}_{1}\right)$ and then put into oven at temperature of $103 \pm$ $2^{\circ} \mathrm{C}$ for $24 \mathrm{~h}$. After treatment, the weight of specimens were remeasured to obtain oven-dry weight (Wo). MC was calculated as follow:

$M C(\%)=\frac{W_{1}-W_{0}}{W_{0}} \times 100 \%$
TS and and WA test were conducted according to JIS A 5908 (2003). The testing consisted of immersion in water at $20^{\circ} \mathrm{C}$ for $24 \mathrm{~h}$. Four specimens of each treatment with dimension of $50 \times 50 \mathrm{~mm}$ were used for TS and WA measurements. Prior and after treatment, the thickness and weight were measured. The TS and WA were calculated by these formulas:

$\operatorname{TS}(\%)=\frac{\Delta h}{h_{0}} \times 100 \%$

$W A(\%)=\frac{\Delta W}{W_{0}} \times 100 \%$

where $\Delta h$ is change of thickness $(\mathrm{mm})$, ho is initial thickness $(\mathrm{mm}), \Delta W$ is change of weight $(\mathrm{g})$ and $W o$ is initial weight $(\mathrm{g})$.

LE measurement was conducted to evaluate the dimensional stability in the plane direction. The measurement was done according to Suzuki and Miyamoto (1998), Miyamoto et al. (2002) and ASTM D-1037 (1999). Two specimens of each treatment with dimension of $280 \mathrm{x}$ $50 \mathrm{~mm}$ were used based on initial measurements taken after boards were dried at $60{ }^{\circ} \mathrm{C}$ for $22 \mathrm{~h}$. The length and change of length of the samples were measured under humid condition of $40{ }^{\circ} \mathrm{C}$ and relative humidity $(\mathrm{RH})$ of $90 \%$ for $120 \mathrm{~h}$ and then under dry condition of $60^{\circ} \mathrm{C}$ for $120 \mathrm{~h}$ using a dial gauge comparator. The LE was calculated by this formula:

$L E(\%)=\frac{\Delta I}{l_{0}} \times 100 \%$

where $\Delta l$ is change of length $(\mathrm{mm})$ and $l 0$ is initial length (mm).

Vertical density profile (VDP) is density gradient in the thickness direction of the boards. It was determined using commercial density profiler based on X-ray system and conducted in Forestry and Forest Products Research Institute (FFPRI) Tsukuba. Four specimens of each board with dimension of $50 \times 50 \mathrm{~mm}$ were used.

\section{Results and Discussion}

\section{Density and Moisture Content}

The target density of the particleboards was 0.72 $\mathrm{g} / \mathrm{cm}^{3}$. After the manufacturing, the real density of each board varied from $0.71 \sim 0.78 \mathrm{~g} / \mathrm{cm}^{3}$ (Fig 1). The trend of board density increased with the increase of hinoki strand ratio to matoa particles. Therefore, the proportion of hinoki strands in the board appeared to influence the board density. This result is corresponding to the study by Sackey et al. (2011), who stated that higher amount of strands resulted in higher density boards. Sackey et al. (2008) stated that this condition may be attributed to the fact that strands are more difficult to compact because of their limited 
ability to rearrange during compression. Considering that hinoki boards are denser than matoa boards, there are two reasons which can be proposed; first is related to the characteristic of wood species and second to the particle size and shape. Hinoki is a softwood species of uniform structure and the original density is low $\left(0.39 \mathrm{~g} / \mathrm{cm}^{3}\right)$ (Kojima et al. 2009) whereas matoa is hardwood of more complex structure and its original density is high $\left(0.8 \mathrm{~g} / \mathrm{cm}^{3}\right)$ (Martawijaya et al. 1981). After board manufacturing, matoa has higher possibility to swell than hinoki. Particle shape and size may influence the possibility of boards to swell after pressing. As it is known that hinoki strands have a high slenderness ratio, it will minimize the possibility to swell and make the boards manufactured become denser than hammermilled-matoa particles.
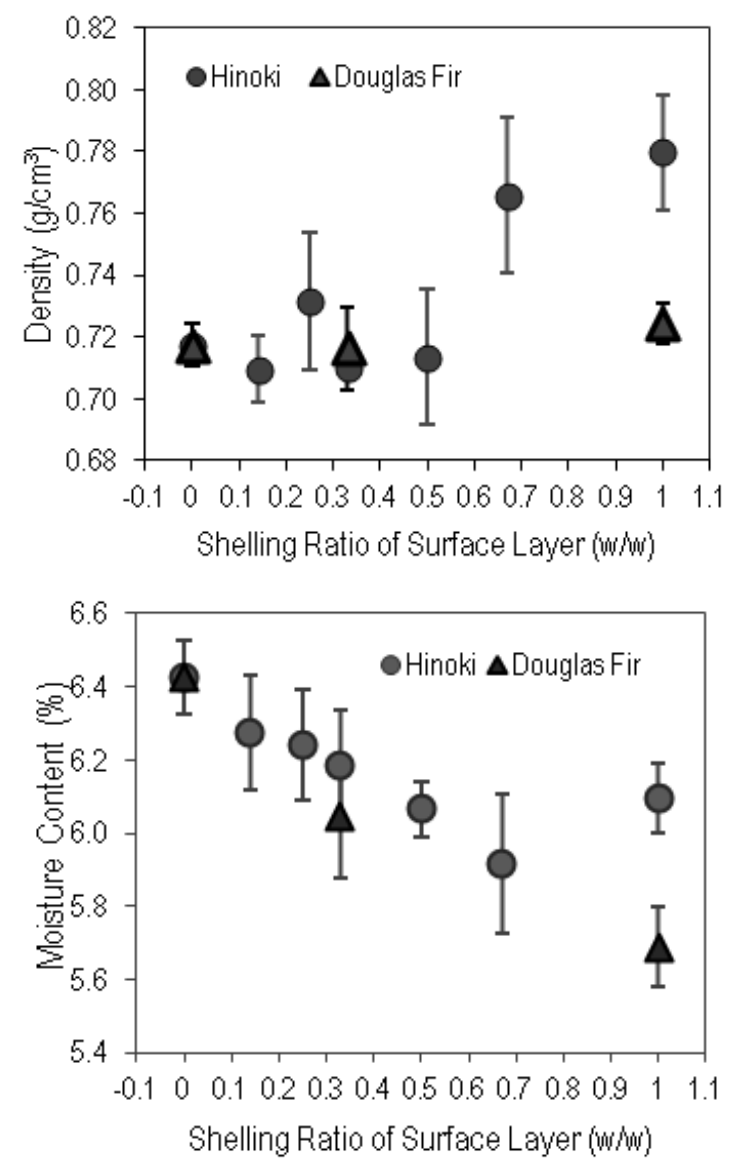

Figure 1. The density and moisture content of particleboards manufactured. Filled circle, particleboard with hinoki strand as surface layer; filled triangle, particleboard with Douglas-fir particle as surface layer; shelling ratio of 0 means matoa single-layer particleboard

Figure 1 shows that the use of hinoki strand results in higher particleboard density than the others. This phenomenon is due to the amount of strands used for particleboard production rather than the species of wood. It is similar to the study of Sackey et al. (2011) who found that the highest density of particleboards was measured from boards with the greatest amount of strands. It was found that there was no difference in density between Matoa and Douglas-fir particleboards although Douglas-fir has originally low density $\left(0.41 \mathrm{~g} / \mathrm{cm}^{3}\right)$. It appeared to be due to rather similar particle shape and size of both Matoa and Douglas-fir particles.

All of the boards had moisture content below $12 \%$ to meet the JIS A-5908 standard requirements. Figure 1 shows that different shelling ratio and particle type affect the board moisture content. Particleboards made from high density materials resulted in higher board moisture content. Higher MC of matoa particleboards appeared due to the high density raw material which contains higher amount of water in the cell wall and is easy to absorp moisture. It can be said that because the rate of moisture release of high density particles during hot pressing was slower than that of low density particles, this could cause higher moisture content in the finish products. Lower MC of Douglas-fir particleboards appeared to be due to the low density raw material. This is different to hinoki particleboards, which were produced from strands. Particleboards made from strands will adsorb more moisture than that from particles (Sackey et al. 2011), therefore higher shelling ratio of hinoki strands resulted in lower moisture content particleboards. By adding higher quality particle on surface layer, the board moisture decreased gradually. It implies that the quality of raw material on surface layer is important to produce high quality particleboards.

\section{Thickness Swelling and Water Absorption}

Figure 2 shows the TS and WA values of the manufactured particleboards. They both show a similar trend. In this study, single layer particleboards using matoa and hinoki resulted in similar TA and WA value, but that of douglas fir was the lowest. The surface proportion of hinoki and Douglas-fir did not necessarily affect the enhancement of TS and WA, except on 1/7 and 1/4 surface proportion of hinoki. A thin hinoki surface layer improved TS and WA value.

In three-layer particleboard, the overall thickness change is the result of both surface and core layers. From figure 2, it can be seen that single-layer matoa and hinoki particleboards have a similar TS value. Therefore, the resultant of thickness swelling is the same, but it shows a different behaviour in particleboard with shelling ratio of $1 / 7$ and $1 / 4$. It should be noted in three layer particleboard with Hinoki strand as surface layer. Strands are more continuous wood elements than particles and hence have higher TS values and absorb more moisture (Sackey et al. 2011). Therefore, higher density boards containing strands can contribute to the greater TS. It seems to give different behavior with three-layer particleboard using Douglas-fir particle as surface layer, which resulted in lower TS value. 

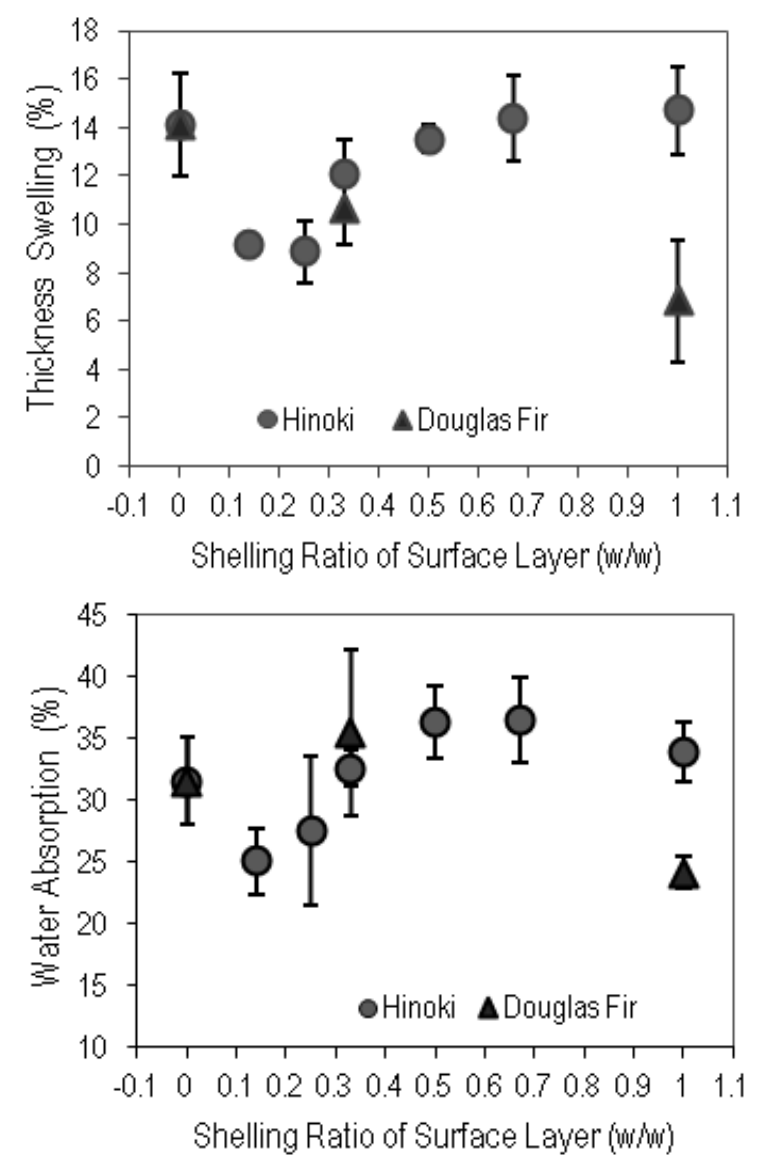

Figure 2. Effect of layer structure and particle characteristic on TS and WA of particleboards. Filled circle, particleboard with hinoki strand as surface layer; filled triangle, particleboard with Douglas-fir as surface layer; shelling ratio of 0 means matoa single-layer particleboard

The value of TS was the greatest in the highest density boards (Chen et al. 2010; Halligan 1970 in Sackey et al. 2011). TS is positively related to density. However, no positive correlation between the average panel density and TS. Chen et al. (2010) reported from several studies regarding the influence of density on TS value that some of the researches are contradictory. In such case, TS was greater in the high density boards than in the low density boards, but in other case it was contrarily. He also stated that the higher density boards absorb water slower, reducing the rate of TS but it will swell more caused by exposure time.

\section{Linear Expansion}

Figure 3 shows that the LE value is affected by shelling ratio of surface layer $(\mathrm{w} / \mathrm{w})$ and wood species. With higher proportion of surface layer with hinoki or Douglas-fir, the LE value decreases. Hinoki has the lowest value of LE compared to Douglas-fir and matoa, respectively. It implies that the dimensional stability of particleboard is affected by the particle source, both the wood species and the shape. With higher proportion of surface layer with hinoki strands, the LE value decreased. It is agreed to Sackey et al. (2011) who found that the strand elements are flatter and have higher slenderness ratio which tend to swell less in parallel direction and contribute very little to LE. The geometry, surface texture and orientation of matoa particles caused them to swell in all directions and the accumulation of this swelling led to higher LE values. Performance of particleboards made from matoa can be enhanced by adding higher quality particle into surface layer such as hinoki strand or Douglas-fir particles.

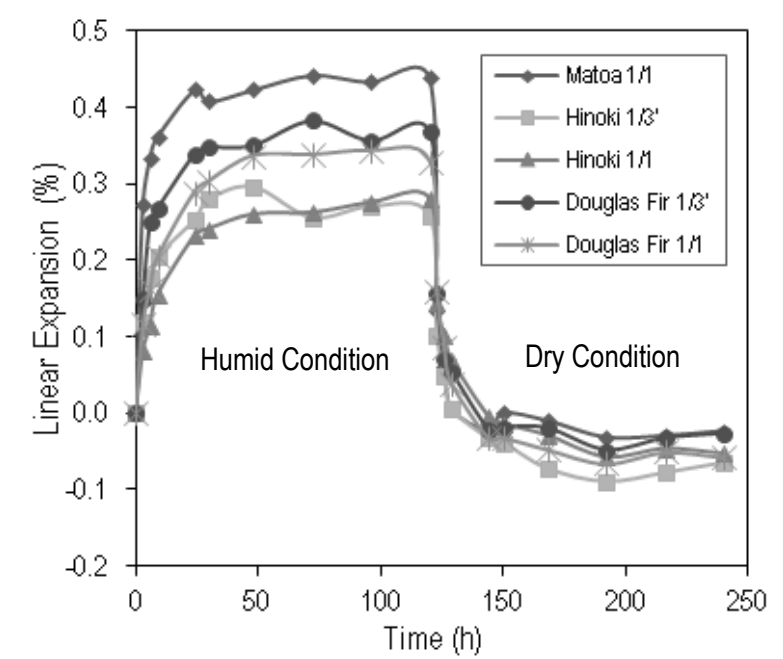

Figure 3. Linear expansion as the effect of shelling ratio and particle type.

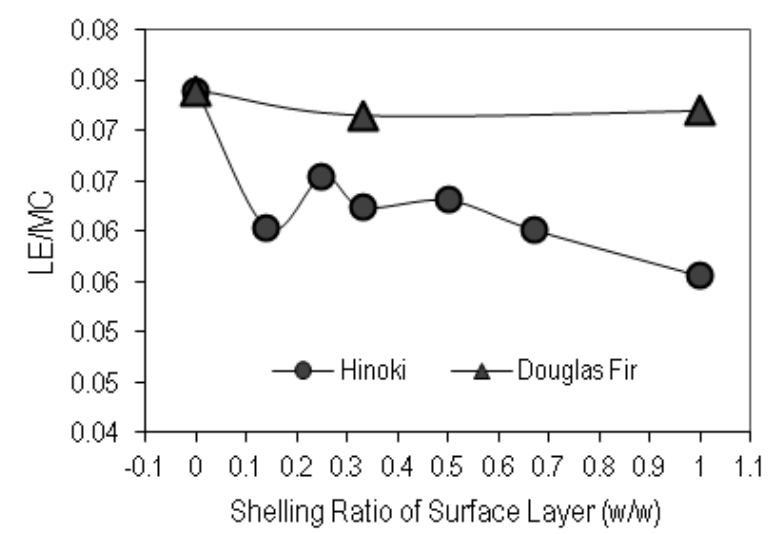

Figure 4. Total linear expansion per unit moisture content change for humid to dry condition. Filled circle, particleboard with hinoki strand as surface layer; filled triangle, particleboard with Douglas-fir particle as surface layer; shelling ratio of 0 means matoa single-layer particleboard.

Linear expansion of all the boards increased rapidly at the beginning of the humid condition and levelled off toward saturation values. It reached the saturation value at approximately after $30 \mathrm{~h}$. This is similar to the study of 
Suzuki and Miyamoto (1998) that particleboard with density of $0.7 \mathrm{~g} / \mathrm{cm}^{3}$ seemed to reach its saturation value at around $30 \mathrm{~h}$. Values of LE per unit MC changed from dry condition (RH 50\%) to humid condition (RH 90\%), as graphically shown in Figure 4. A quadratic curve can be used to describe the decreasing LE/MC values with the increasing shelling ratio. The $R^{2}$ of the curves was 0.66 .

Hinoki has the lowest value of LE, then followed by douglas-fir and matoa, respectively. This result is similar to that of Sackey et al. (2011) who reported that boards with shorter and thicker particles recorded higher LE and boards with more slender strands had lower LE. Miyamoto et al. (2002) also reported that boards with small particles had higher LE. It implies that the dimensional stability of particleboard is affected by the particle source, both the wood species and the shape. The quality of particleboards made from matoa can be enhanced by adding higher quality particle such as hinoki strand or Douglas-fir particles into the surface layer.

\section{Vertical Density Profile}

Commonly, VDP is characterized by high density surface region and low density core region. Kollmann et al. (1975) stated that the minimum values for density always in the center of the boards. Figure 5 is representative VDP values of particleboards manufactured as the effects of particle type and shelling ratio. It shows that single layer particleboard from matoa has the lowest difference of density between surface region and core region compared to that of single layer particleboard from Douglas-fir and hinoki, respectively. It implies that particleboard made from higher density wood species resulted in lower difference density profile between surface and core region than that of lower density wood species. The term of higher quality material is related to the particle characteristic, where low density and high slenderness ratio of material have the important role. Since it has the lowest density and the highest slenderness ratio compared to other materials used in this study, particleboards made of hinoki strand had the highest density profile in surface layer than the others.

In three-layer particleboards, the increase of hinoki strand shelling ratio increased the density of surface region higher than that of Douglas-fir. Higher density and lower slenderness ratio of douglas-fir particles caused lower density profile in surface layer than those of hinoki surface layer. That figure also shows a typical density gradient for particleboard with high density layers just inside the board surface as noted by Suzuki and Miyamoto (1998). Threelayer particleboards with different wood species in this study gave low difference of density between surface and core region. Chen et al. (2010) reported several studies about VDP and it has been recognized as one of the influencial factors affecting physical and mechanical properties of wood panels. The higher density in the surface layers affects correspondenly higher bending strength and higher resistance to absorption and swelling (Kollmann et al. 1975).

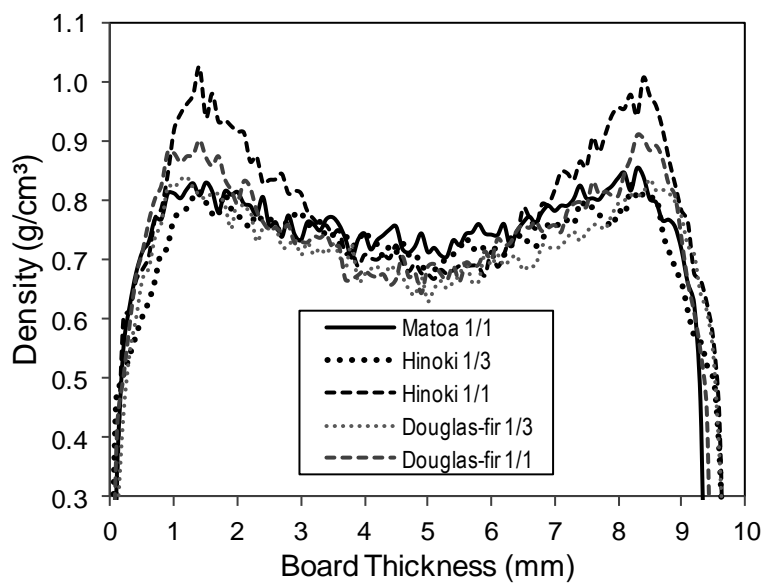

Figure 5. Typical vertical density profile of particleboards at various shelling ratio and particle type.

\section{Conclusions}

In this study, enhancement of the physical properties of particleboard production using low quality matoa particles was examined. The improvement was conducted by adding surface layer with higher quality wood particles such as hinoki strands or Douglas-fir particles. Higher shelling ratio based on weight of hinoki and Douglas-fir as surface layer resulted in higher performance of three-layer particleboard. Hinoki strands with shelling ratio of $1 / 1$ showed the best performance in the board density. Douglas-fir particles with shelling ratio of $1 / 1$ showed the best performance in moisture content, thickness swelling and water absorption. In terms of particle type, hinoki strands showed the best performance in board density and linear expansion while Douglas-fir particles showed the best performance in moisture content, thickness swelling and water absorption. It can be concluded that improvement of low quality materials for particleboard production can be conducted by adding high quality materials as the surface layer.

\section{References}

American Society for Testing and Materials. 1999. Standard Method for Evaluating The Properties of Wood-Base Fiber and Particle Panel Materials. ASTM D-1037-99.

Chen, S.; C. Du; R. Wellwood. 2010. Effect of Panel Density on Major Properties of Oriented Strandboard. Wood and Fiber Science 42 (2): 177-184.

Japanese Industrial Standard. 2003. Particleboards. JIS A 5908. Japanese Standards Association. Tokyo.

Kojima, Y.; S. Nakata; S. Suzuki. 2009. Effects of Manufacturing Parameters on Hinoki Particleboard Bonded with MDI Resin. Forest Prod. J. 59(5):29-34.

Kollmann, F.F.P.; E.W. Kuenzi; A.J. Stamm. 1975. Principles of Wood Science and Technology. Vol II: 
Wood Based Material. Springer-Verlag. Berlin Heidelberg New York.

Martawijaya, A.; I. Kartasujana; K. Kadir; S.A. Prawira. 1981. Atlas Kayu Indonesia. Jilid I. Pusat Penelitian dan Pengembangan Kehutanan. Bogor.

Maloney, T.M. 1993. Modern Particleboard and Dry-Process Fiberboard Manufacturing. Miller Freeman Inc. San Francisco.

Miyamoto, K.; S. Nakahara; S. Suzuki. 2002. Effect of Particle Shape on Linear Expansion of Particleboard. J Wood Sci 48:185-190.

Moslemi, A.A. 1974. Particleboard. Vol 1: Materials. Southern Illinois University Press. Carbondale.

Sackey, E.K.; K.E. Semple; S.W. Oh; G.D. Smith. 2008. Improving Core Bond Strength of Particleboard through Particle Size Redistribution. Wood and Fiber Science 40 (2):214-224.

Sackey, E.K.; C. Zhang; Y. Tsai; A. Prast; G.D. Smith. 2011. Feasibility of A New Hybrid Wood Composite Comprising Wood Particles and Strands. Wood and Fiber Science 43(1):11-20.

Suzuki, S.; K. Miyamoto. 1998. Effect of Manfacturing Parameters on The Linear Expansion and Density Profile of Particleboard. J Wood Sci 44: 444-450.

Suzuki, S.; K. Takeda. 2000. Production and Properties of Japanese Oriented Dtrand Board I: Effect of Strand
Length and Orientation on Strength Properties of Sugi Oriented Strand Board. J Wood Sci 46:289-295.

Wilczynski, A.; M. Kociszewski. 2010. Elastic Properties of The Layers of Three-Layer Particleboards. Eur. J. Wood Prod. DOI 10.1007/s00107-010-0497-8

Youngquist, J.A. 1999. Wood-Based Composites and Panel Products. In Wood Handbook: Wood as an Engineering Material.

Muhammad Navis Rofii and Tibertius Agus Prayitno

Department of Forest Products Technology

Faculty of Forestry Universitas Gadjah Mada

Jl. Agro 1 Bulaksumur Yogyakarta 55281 Indonesia

Tel. : : +62 274512102

Fax. : : +62 274550541

E-mail : navis_r@yahoo.fr / navis_r@ugm.ac.id

Muhammad Navis Rofii, Satomi Yumigeta and

Shigehiko Suzuki

Department of Environment and Forest Resource Science

Faculty of Agriculture Shizuoka University

Ohya 836, Suruga-ku, Shizuoka $422-8529$ Japan

Tel. : : : +81542384854

Fax. : : +81542373028

E-mail : afssuzu@ipc.shizuoka.ac.jp 